\title{
Controlled release of paclitaxel from a self-assembling peptide hydrogel formed in situ and antitumor study in vitro
}

This article was published in the following Dove Press journal:

International Journal of Nanomedicine

26 September 2011

Number of times this article has been viewed

\author{
Jingping Liu',2 \\ Lanlan Zhang' \\ Zehong Yang' \\ Xiaojun Zhao ${ }^{1,3}$ \\ 'West China Hospital Laboratory \\ of Nanomedicine and Institute for \\ Nanobiomedical Technology and \\ Membrane Biology; ${ }^{2}$ Key Laboratory \\ of Transplant Engineering and \\ Immunology, West China Hospital, \\ Sichuan University, Chengdu, China; \\ ${ }^{3}$ Center for Biomedical Engineering, \\ Massachusetts Institute of Technology, \\ Cambridge, MA, USA
}

Background: A nanoscale injectable in situ-forming hydrogel drug delivery system was developed in this study. The system was based on a self-assembling peptide RADA16 solution, which can spontaneously form a hydrogel rapidly under physiological conditions. We used the RADA16 hydrogel for the controlled release of paclitaxel (PTX), a hydrophobic antitumor drug.

Methods: The RADA16-PTX suspension was prepared simply by magnetic stirring, followed by atomic force microscopy, circular dichroism analysis, dynamic light scattering, rheological analysis, an in vitro release assay, and a cell viability test.

Results: The results indicated that RADA16 and PTX can interact with each other and that the amphiphilic peptide was able to stabilize hydrophobic drugs in aqueous solution. The particle size of PTX was markedly decreased in the RADA16 solution compared with its size in water. The RADA16-PTX suspension could form a hydrogel in culture medium, and the elasticity of the hydrogel showed a positive correlation with peptide concentration. In vitro release measurements indicated that hydrogels with a higher peptide concentration had a longer half-release time. The RADA16-PTX hydrogel could effectively inhibit the growth of the breast cancer cell line, MDA-MB-435S, in vitro, and hydrogels with higher peptide concentrations were more effective at inhibiting tumor cell proliferation. The RADA16-PTX hydrogel was effective at controlling the release of PTX and inhibiting tumor cell growth in vitro.

Conclusion: Self-assembling peptide hydrogels may work well as a system for drug delivery. Keywords: self-assembling peptide, hydrogel, paclitaxel, drug delivery, antitumor

\section{Introduction}

Paclitaxel (PTX) is one of the most effective antitumor drugs found in nature in the past few decades. ${ }^{1,2}$ It promotes polymerization of tubulin dimers, which results in the formation of highly stable nonfunctional microtubules in the absence of guanosine triphosphate and microtubule-associated proteins, ultimately preventing cell division., Because of its unique mechanism of action against tumor cells, PTX has demonstrated excellent therapeutic efficacy for a wide range of cancers, although it works especially well for treatment of ovarian and breast cancers. ${ }^{1}$

Paclitaxel is hydrophobic and is poorly soluble in water. Currently, the PTX used clinically is in a vehicle composed of Cremophor ${ }^{\circledR}$ EL and ethanol at a 50:50 (v/v) ratio. Cremophor EL is a nonionic polyethoxylated castor oil solubilizer that can enhance PTX solubility. However, this solvent causes severe hypersensitive reactions and cytotoxicity and is incompatible with polyvinyl chloride, which is commonly used in injection systems. ${ }^{2,5}$ In addition, PTX can cause serious side effects at excessive 
doses, such as bone marrow suppression and cardiac rhythm disturbances. ${ }^{3}$ Therefore, researchers have developed a variety of vehicles, including microspheres, nanoparticles, surgical pastes, polymeric micelles, and hydrogels, to control PTX release and to eliminate the toxicity of Cremophor EL to the body. ${ }^{1,3}$

Hydrogels have been commonly used in drug delivery, and various natural polymers and synthetic copolymer hydrogels, such as chitosan, hyaluronic acid, alginate, polymethyl methacrylate, and polyethylene glycol, have been studied. These compounds usually form hydrogel-drug complexes outside of the body and are then delivered into the body. ${ }^{5-9}$ However, the formation of hydrogels frequently involves ultraviolet photopolymerization and various chemical cross-linking techniques, and there is a potential risk that toxic reagents may fail to be removed completely prior to hydrogel implantation. Furthermore, some hydrogels have high elasticity, which generally prevents their extrusion through a syringe needle. ${ }^{6}$ Therefore, an alternative vehicle is necessary.

Self-assembling peptides are a type of designed biomaterial and have been used in a number of biomedical applications, such as cell culture, tissue engineering, and drug delivery. ${ }^{10-13}$ Self-assembling peptides can spontaneously assemble to cross-linked nanofibers of 10-20 $\mathrm{nm}$ in diameter and form a stable second structure of $\beta$-sheet in aqueous solution. Under physiological conditions, the peptide solution can rapidly self-assemble into hydrogels, which contain more than $99 \%$ (w/v) water. ${ }^{11,12,14}$ Previous studies have used RADA16 peptide to slow the release of proteins and localized therapies through injection into a particular tissue. ${ }^{15-18}$ Because the process of hydrogel formation is ionic-dependent and is irrelevant with ultraviolet or chemical cross-linking, it was supposed that RADA16 may serve well as a potential drug delivery vehicle.

The purpose of this study was to develop an injectable in situ gel drug delivery system based on a self-assembling peptide. The incorporation of peptide and drug was achieved simply by mix and magnetic stirring. To investigate the interaction of RADA16-PTX, the release properties of hydrogel, and antitumor efficiency in the current study, we performed a morphology analysis, circular dichroism, dynamic light scattering, rheological test, in vitro release test, and a cell viability test.

\section{Materials and methods Incorporation of peptide and PTX}

Self-assembling peptide RADA16 (n-RADARADARADARADA-c) was commercially synthesized and purified by Shanghai Biotech Bioscience and Technology Co Ltd (Shanghai, China). Paclitaxel was purchased from the National Institute for the Control of Pharmaceutical and Biological Products (Beijing, China). Peptide solutions at concentrations of 5 and $10 \mathrm{mg} / \mathrm{mL}$ were prepared by dissolving RADA16 peptide powder in Milli-Q water with 10 minutes of sonication. The peptide solution incorporated with PTX was prepared by adding peptide solution (5 or $10 \mathrm{mg} / \mathrm{mL}$ ) into a glass vial with PTX at a final concentration of $1 \mathrm{mg} / \mathrm{mL}$, followed by magnetic stirring for 48 hours, whereas the control sample was formed by adding Milli-Q water instead of peptide solution. All of the vials and solvents were sterilized, and the samples were prepared in a biological safety cabinet to avoid possible contamination for cell culture experiments.

\section{Atomic force microscopy}

The morphology of samples was observed using an atomic force microscope (SPI4000 Probe Station, Seiko Instruments Inc, Chiba, Japan) with a tapping mode. For the preparation of the samples, RADA16 solution or RADA16PTX suspension was diluted 50 times in Milli-Q water, and then $10 \mu \mathrm{L}$ of diluted solution was evenly placed on a freshly cleaved mica substrate. The mica surface was then rinsed with Milli-Q water to remove unattached peptide and air-dried. The measurement was performed at room temperature and all images were recorded with a resolution of $512 \times 512$ pixels. The typically scan parameters were set as follows: scan speed $1.00 \mathrm{~Hz}$, amplitude $1-1.2 \mathrm{~V}$, and integral and proportional gains of $0.2-0.3$ and $0.03-0.04$, respectively.

\section{Dynamic light scattering}

The particle size distribution of the RADA16 solution and RADA16-PTX suspension was investigated on a NanoParticle Size Analyzer (LB-550, Horiba Ltd, Kyoto, Japan) with appropriate viscosity and refractive index settings, and the temperature was maintained at $25^{\circ} \mathrm{C}$ during measurement. The RADA16 solution and RADA16-PTX suspension was diluted 20 times with Milli-Q water, and each sample was tested at least three times to generate the intensity-based size distribution plot report.

\section{Circular dichroism spectroscopy}

The circular dichroism measurement was performed at $25^{\circ} \mathrm{C}$ on an Aviv Model 400 (Aviv Biomedical Inc, Lakewood, NJ) with a $2 \mathrm{~mm}$ path length quartz cuvette. All samples of RADA16 solution and RADA16-PTX suspension were 
diluted 50 times with Milli-Q water before the test, and then circular dichroism spectra were collected at $1 \mathrm{~nm}$ intervals and $1 \mathrm{~nm}$ bandwidths from 190 to $260 \mathrm{~nm}$, with three time scans for the average. All spectra were corrected by subtracting the baseline, and the data were expressed as molar ellipticity $[\theta]$ with units of $\mathrm{deg} \cdot \mathrm{cm}^{2} \cdot \mathrm{dmol} / \mathrm{L}$. The secondary structure fractions of the peptide were calculated by free software CDPro using a modified Contin method (CONTINLL program) and comparison with a set of reference proteins.

\section{Rheological analysis}

The rheological properties of RADA16-PTX suspension were measured on a rheometer (AR2000, TA Instruments, New Castle, DE) with a $20 \mathrm{~mm}$ diameter and a $1^{\circ}$ steel cone with $25 \mu \mathrm{m}$ truncation gap. A $70 \mu \mathrm{L}$ sample of RADA16-PTX suspension was placed on the plate of the rheometer and a trap was placed around the cone to seal the liquid. The storage $\left(G^{\prime}\right)$ and loss $\left(G^{\prime \prime}\right)$ modulus was measured at $37^{\circ} \mathrm{C}$, and the parameters used for the frequency sweep tests were strain $0.5 \%$ and frequency range $0.01-100 \mathrm{rad} / \mathrm{sec}$. For rheological testing of peptide-PTX hydrogel, RADA16-PTX suspension was first induced to gel by adding $70 \mu \mathrm{L}$ of phosphatebuffered saline solution. After equilibrating for one minute, the excess solution was taken off, and the measurement was performed as described above.

\section{In vitro release measurement}

The release of PTX from RADA16-PTX hydrogel was carried out in vitro in phosphate-buffered saline solution. RADA16-PTX suspension $100 \mu \mathrm{L}$ was dripped to the bottom of a cuvette, then $10 \mathrm{~mL} 0.1 \mathrm{M}$ phosphate-buffered saline $(\mathrm{pH} 7.4)$ with $0.3 \%(\mathrm{w} / \mathrm{v})$ sodium dodecyl sulfate was added gently and incubated at $37^{\circ} \mathrm{C}$ for an indicated time period. The concentration of PTX in phosphate-buffered saline was determined by reversed-phase high-pressure liquid chromatography, performed with a Shimadzu LC-20 A high-pressure liquid chromatography system (Shimadzu Corporation, Kyoto, Japan). The mobile phase consisted of methanol and water (70:30). The injection volume was $20 \mu \mathrm{L}$ and the mobile phase flow rate was $1.0 \mathrm{~mL} / \mathrm{min}$. Separation was achieved by a C-18 column (Shim-pack VP-ODS, $150 \mathrm{~mm} \times 4.6 \mathrm{~mm}$, $5 \mu \mathrm{m})$. The column eluate was monitored at a wavelength of $227 \mathrm{~nm}$. A calibration curve of PTX was constructed to determine the percentage of PTX released from the peptide hydrogel. At the end of the release test, the supernatant in the release medium was collected and measured by atomic force microscopy.

\section{In vitro antitumor cell study}

The human breast cancer cell line MDA-MB-435S was used for the in vitro cell viability study. The cells were cultured in L-15 medium containing 10\% fetal bovine serum at $5 \% \mathrm{CO}_{2}$. When cells reached $85 \%$ confluence, they were detached from cell culture flasks with trypsin and resuspended in cell culture medium at a concentration of $10^{5}$ cells $/ \mathrm{mL}$. After $200 \mu \mathrm{L}$ of the cell suspension was added to each well of a flat-bottom 96-well plate and incubated overnight, the culture medium was removed. Twenty microliters of diluted PTX (Taiji Pharmaceutical Co Ltd, Sichuan, China), RADA16, or RADA16-PTX suspension was then pipetted into the central bottom of the well and equilibrated with $200 \mu \mathrm{L}$ of culture medium to initiate peptide gel formation. The culture medium for all groups was changed daily. The cell viability assay was carried out at prearranged times.

Cell viability was estimated using a modified MTT assay in this study. Briefly, at different time points, $200 \mu \mathrm{L}$ of serum-free medium and $20 \mu \mathrm{L}$ of MTT solution $(5 \mathrm{mg} / \mathrm{mL}$ in phosphate-buffered saline) were added to each sample, followed by incubation at $37^{\circ} \mathrm{C}$ for four hours to allow MTT formazan formation. The medium was then removed, and the converted dye was dissolved with $200 \mu \mathrm{L}$ of $10 \%$ sodium dodecyl sulfate in $0.01 \mathrm{M} \mathrm{HCl}$. After all crystals were solubilized, the optical density of the solution was determined at $570 \mathrm{~nm}$ against an sodium dodecyl sulfate solution blank using an enzyme-linked immunosorbent assay plate reader. Four parallel replicates were read for all samples. Cell viability was calculated by the following equation:

$$
\text { Cell viability }(\%)=\left(\mathrm{Abs}_{\text {test cells }} / \mathrm{Abs}_{\text {control cells }}\right) \times 100 \%
$$

in which $\mathrm{Abs}_{\text {test cells }}$ and $\mathrm{Abs}_{\text {control cells }}$ were the absorbencies of cells with different treatments and cells incubated with medium only, respectively.

Cell viability was also assessed by a Live/Dead assay. A work solution containing both $1 \mu \mathrm{M}$ calcein $\mathrm{AM}$ and $2 \mu \mathrm{M}$ ethidium homodimer in phosphate-buffered saline were prepared according to the Live-Dead assay (Molecular Probes $^{\circledR}$, Invitrogen, Carlsbad, CA) package instructions, and $200 \mu \mathrm{L}$ of work solution was added to each well. All cells were imaged using a fluorescence microscope.

\section{Statistical analysis}

All quantitative data were shown as the mean \pm standard deviation. Statistical analysis was performed using SPSS 
software (version 11.5, Chicago, IL) with one-way analysis of variance and a $95 \%$ confidence level.

\section{Results and discussion Interaction of RADA I 6 and PTX}

The self-assembling RADA16 peptide is a designed nanoscale biomaterial, the sequence of which contains alternating hydrophilic and hydrophobic amino acid residues. Paclitaxel is a hydrophobic antitumor drug that is poorly soluble in water. After stirring for 48 hours, PTX in RADA16 solution was changed to a colloidal suspension, while the same component in pure water was still clear, and a significant amount of PTX powder was visible (Figure 1). The data suggested that RADA16 interacted with PTX in aqueous solution. Figure $2 \mathrm{~A}$ and $\mathrm{C}$ showed the typical morphology of RADA16, which consisted of multiple cross-linked nanofibers that were $21.5 \pm 3.3 \mathrm{~nm}$ in width and $2.2 \pm 0.2 \mathrm{~nm}$ in height. After stirring with PTX for 48 hours, the morphology of RADA16 changed. Some bulged nanofibers and aggregates could be seen (Figure 2B and D), and the width and height of those nanofibers were $45.3 \pm 10.6 \mathrm{~nm}$ and $5.6 \pm 2.3 \mathrm{~nm}$, respectively. Some PTX particles coated by peptide nanofibers were also observed (Figure 2B and D). From the circular dichroism analysis, the RADA16 peptide had a typical $\beta$-sheet structure (minimum molar ellipticity at $215-217 \mathrm{~nm}$ and maximum at $195-206 \mathrm{~nm}$ ), with $50.6 \% \beta$-sheet content (Figure 3 and Table 1, S (r) $+\mathrm{S}$ [d]) according to the CDPro software analysis. ${ }^{19}$ However, when RADA16 was stirred

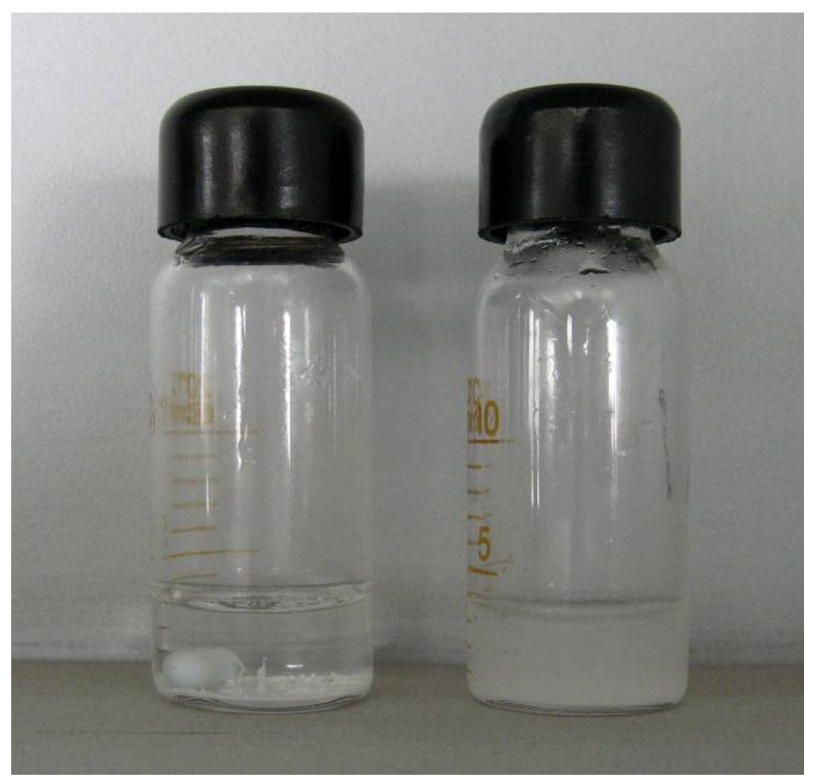

Figure I After stirring for 48 hours, paclitaxel I mg/mL in pure water was still clear (left). However, the same concentration of paclitaxel in 0.5\% RADAI6 aqueous solution was changed to a colloidal suspension (right).

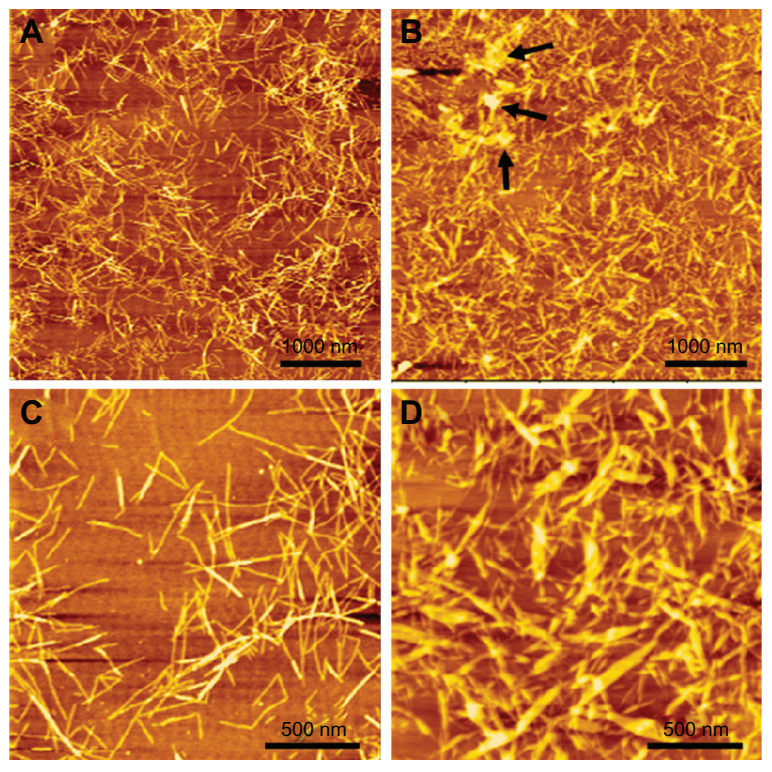

Figure 2 Morphology of RADAl6 peptide and RADAI6-PTX suspension. (A and C) Nanofibers in RADAI6 solution. (B and D) Nanofibers in RADAI6PTX suspension. It can be seen that some PTX particles were coated by RADAI6 nanofibers (black arrowhead).

Abbreviation: PTX, paclitaxel.

with PTX for 48 hours, there was an approximately $18.4 \%$ decrease in the $\beta$-sheet content and a $19.8 \%$ increase in the unordered structure content. Dynamic light scattering measurements showed that the diameter of nanofibers from a pure RADA16 solution was in the range of 10-50 nm. When PTX was stirred with $0.5 \%$ and $1 \%$ RADA16 solution, the mean particle sizes were $2744.7 \pm 551.3 \mathrm{~nm}$ and $2569.4 \pm 434.9 \mathrm{~nm}$, respectively, but there was no difference between the $0.5 \%$ and $1 \%$ RADA16 solution groups (Figure 4). When PTX was stirred with Milli-Q water, the mean particle size was over $6 \mu \mathrm{m}$, and dynamic light scattering measurements could not be conducted.

The circular dichroism data showed that the $\beta$-sheet structure of RADA 16 was impaired to some extent by the addition of PTX, a result that was in accordance with the change in morphology on atomic force microscopy. The particle size of PTX was obviously decreased in the RADA16 solution compared with that in the water. All of the data indicated that RADA16 did not simply mix with PTX but rather interacted with it. As illustrated in Figure 5, RADA16 consists of repeated sequences of Arg-Ala-Asp-Ala, in which Arg and Asp are hydrophilic amino acid residues and Ala is a hydrophobic amino acid residue; the $\beta$-sheet structure of the peptide therefore had both hydrophobic and hydrophilic regions. ${ }^{15}$ Because PTX is a typical hydrophobic compound, the hydrophobic regions of peptide would be adsorbed to the hydrophobic surface of separated PTX particles under 


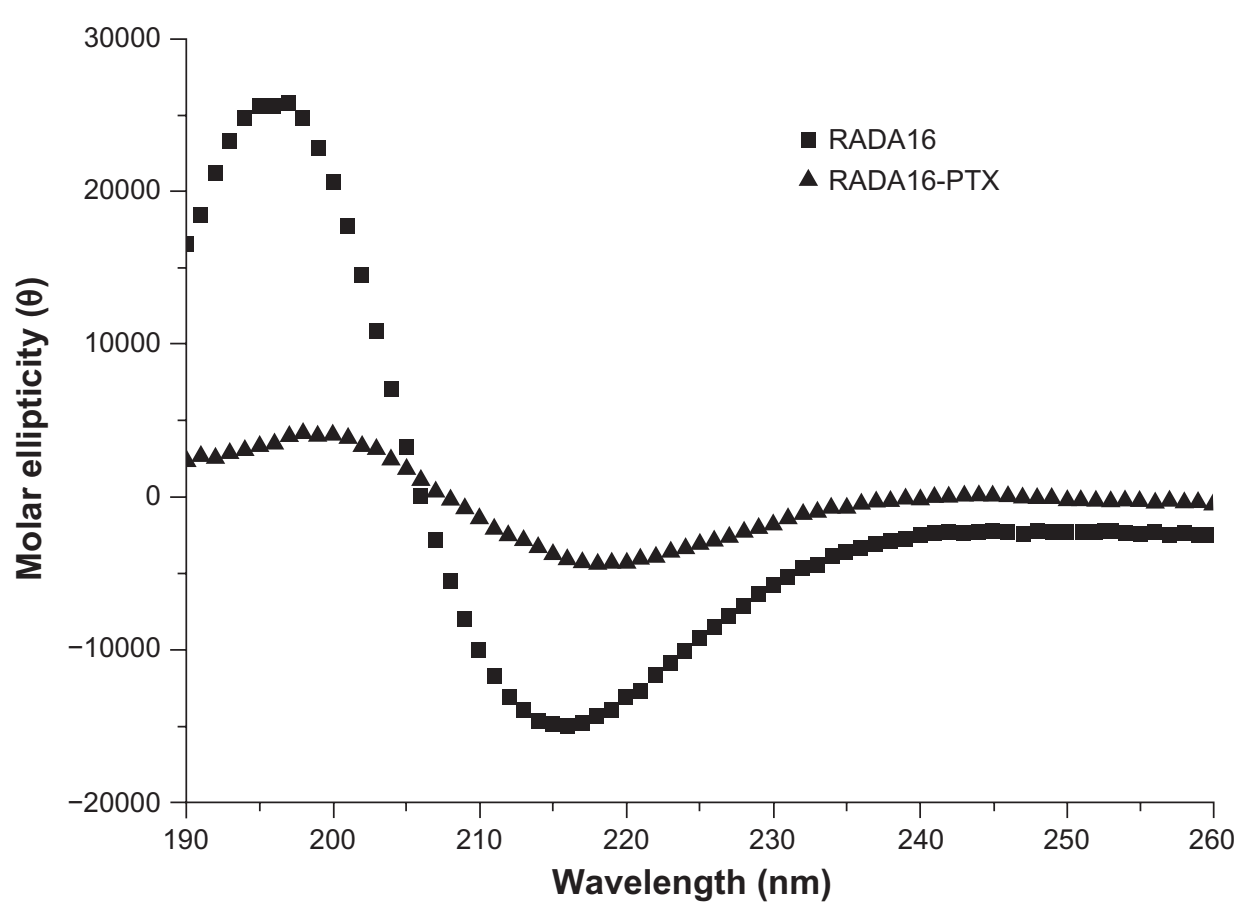

Figure 3 Secondary structure of RADAI6 and RADAI6 with incorporated paclitaxel. RADAI6 peptide had a typical $\beta$-sheet structure. However, when paclitaxel was incorporated with RADA I6, there was an obvious decrease in $\beta$-sheet structure.

stirring, a phenomenon that resulted in the impaired $\beta$-sheet structure of RADA16 shown in the circular dichroism data. The atomic force microscopy images showed that there were many bulged RADA16 nanofibers, which may have resulted from PTX molecules that were incorporated with nanofibers or from the aggregation of nanofibers induced by hydrophobic interactions. The data indicate that the self-assembling peptide and PTX could interact with each other and that the amphiphilic peptide was able to stabilize hydrophobic drugs in aqueous solution, a finding that was in agreement with previous reports. ${ }^{20-22}$ This type of interaction also helps to increase the solubility of PTX and decrease the mean particle size of PTX in RADA16 solution under stirring. Therefore, the RADA16-PTX suspension could potentially be injected into the body with a syringe needle. These results indicated that PTX molecules and particles can coexist in RADA16PTX suspension, and stabilized PTX can be obtained in this system. However, further investigation is necessary to determine the percentage of each state in the complexes.

Table I The calculated secondary structure fractions of peptide

\begin{tabular}{lllllll}
\hline Items & \multicolumn{7}{l}{ Secondary structure fractions (\%) } \\
\cline { 2 - 7 } & $\mathbf{H}(\mathbf{r})$ & $\mathbf{H}(\mathbf{d})$ & $\mathbf{S ~ ( r )}$ & $\mathbf{S ~ ( d )}$ & Turn & Unrd \\
\hline RADAI6 & 0.4 & 1.9 & 33.8 & 16.8 & 20.4 & 26.7 \\
RADAI6-PTX & 0.2 & 3.4 & 27.1 & 14.2 & 21.8 & 33.3 \\
\hline
\end{tabular}

Abbreviations: $H(r)$, regular $\alpha$-helix; $H(d)$, distorted $\alpha$-helix; $S(r)$, regular $\beta$-strand; $S(d)$, distorted $\beta$-strand; Turn, $\beta$-turn structure; Unrd, unordered structure.

\section{Characterization of RADA I6-PTX hydrogel formation}

The gelation of RADA16-PTX suspension was characterized by rheometry. As in previous reports, the RADA16 solution was able to form a hydrogel in ionic environments, such as phosphate-buffered saline, physiological saline, and body fluid. However, could the RADA16-PTX suspension gel under physiological conditions? The test was performed at $37^{\circ} \mathrm{C}$, and phosphate-buffered saline was used to simulate body fluid. The storage modulus $\left(\mathrm{G}^{\prime}\right)$ and loss modulus $\left(G^{\prime \prime}\right)$ responded to the elasticity and viscosity of materials, respectively. As shown in Figure 6, the frequency sweep indicated that the value of the storage modulus $\left(\mathrm{G}^{\prime}\right)$ in the RADA16-PTX suspension was larger than that of the loss modulus $\left(\mathrm{G}^{\prime \prime}\right)$ both in $0.5 \%$ and $1 \%$ RADA16, and all of the low values $(<10 \mathrm{~Pa})$ for the storage and loss moduli were typical for low viscosity systems with a low degree of elasticity. With the addition of medium, significant changes occurred, ie, the storage and loss moduli increased. The storage modulus of $0.5 \%$ RADA 16 was over $300 \mathrm{~Pa}$ and that of $1 \%$ RADA16 was over $1000 \mathrm{~Pa}$, whereas the original values for both $0.5 \%$ and $1 \%$ RADA16 were under $10 \mathrm{~Pa}$. The great increase in the storage modulus suggested the formation of a strong hydrogel. At the mean time, it was observed that the storage modulus of $0.5 \%$ RADA 16 hydrogel was much lower than that of the $1 \%$ RADA16 hydrogel, which indicated that the concentration 


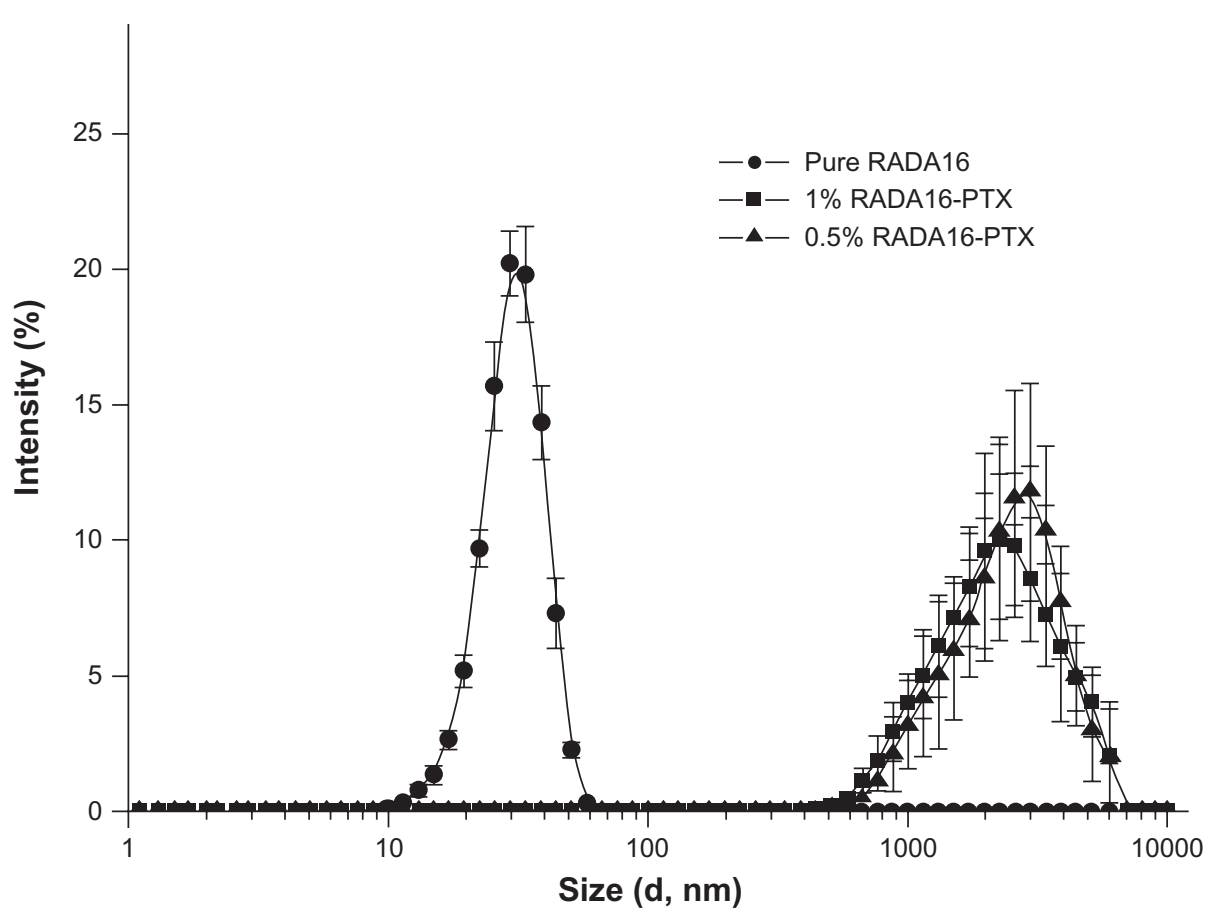

Figure 4 Size distribution of pure RADAI6 solution and RADAI6-PTX suspension with different peptide concentrations. There was no significant difference between the $0.5 \%$ and I\% RADAI6-PTX groups.

Abbreviation: PTX, paclitaxel.

of peptide had a positive correlation with the elasticity of the hydrogel. The results demonstrated that the RADA16-PTX suspension could form a highly elastic hydrogel under physiological conditions. As an in situ forming gel drug delivery system, the ideal vehicle should be an injectable solution in vitro and change to a gel in vivo. RADA16 was able to form a hydrogel rapidly under physiological conditions without heating or chemical reaction, making it a favorable vehicle for drug delivery.

\section{In vitro PTX release from RADA I6-PTX hydrogel}

Paclitaxel is a hydrophobic drug that is poorly soluble in water. To maintain sink conditions throughout the release

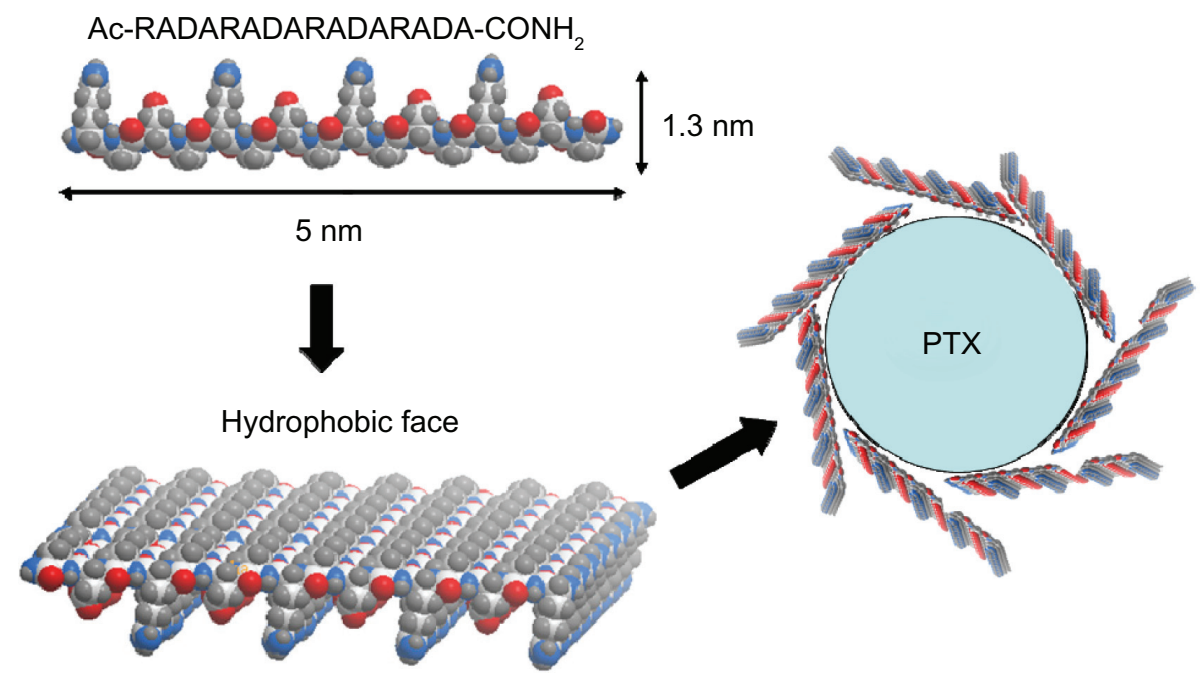

Hydrophilic face

Figure 5 Schematic representation of the interaction between RADAI 6 peptides and PTX. All alanine residues are present on the hydrophobic face of the RADAI6 $\beta$-sheet, and the hydrophilic face consists of alternating arginine and aspartic acid residues (carbon, white; oxygen, red; nitrogen, blue; hydrogen, gray).

Abbreviation: PTX, paclitaxel. 

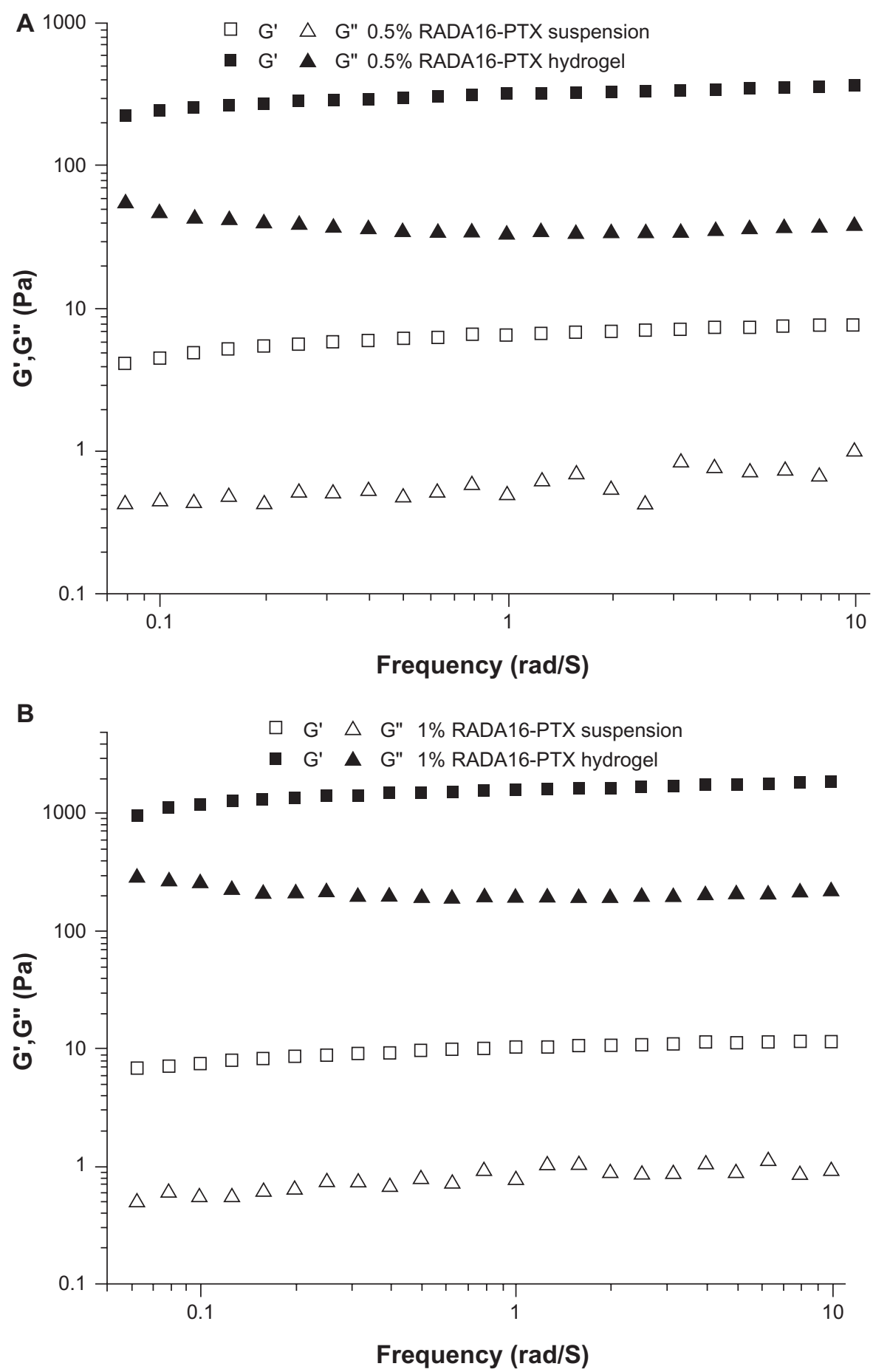

Figure 6 Frequency sweep of RADA I6-PTX hydrogel in rheological analysis. (A) 0.5\% RADAI6-PTX and (B) I\% RADAI6-PTX. The results showed that the storage modulus of $0.5 \%$ RADA I6-PTX hydrogel was much lower than that of I\% RADA I6-PTX hydrogel.

Abbreviation: PTX, paclitaxel.

process, sodium dodecyl sulfate was added to the release medium to increase the solubility of PTX. ${ }^{5}$ The release was observed over a period of five days. As shown in Figure 7B, the RADA16-PTX suspension could form a milky-white gel in phosphate-buffered saline, and the volume of hydrogel was obviously reduced over the release time. The resulting release profiles of PTX from the RADA16-PTX hydrogels are shown in Figure 7A. When a hydrogel was prepared with $1 \%$ RADA 16 , approximately $40 \%-45 \%$ of incorporated PTX was released from the hydrogel within the first day, with a half-release time of 24-30 hours. In contrast, more than $60 \%$ of the PTX was released from the hydrogel within one day for 


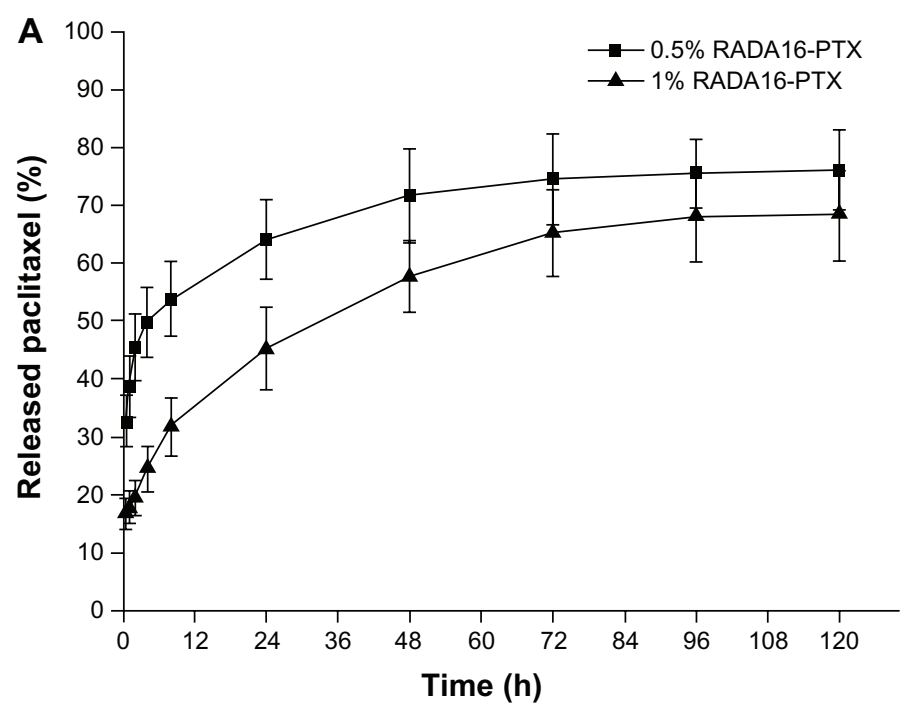

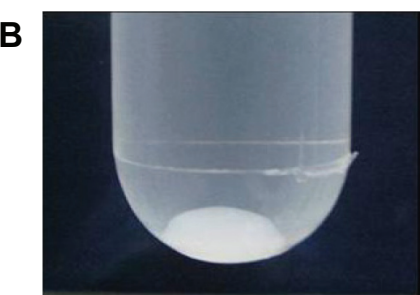

$0.5 \mathrm{~h}$ after release

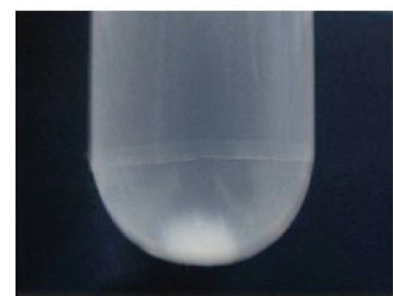

$48 \mathrm{~h}$ after release

Figure 7 In vitro release of PTX from RADA 16-PTX hydrogel with different peptide concentrations. (A) The rates of released PTX at different points and (B) photographs of I\% RADA I6-PTX hydrogel in phosphate-buffered saline at 0.5 hours and 48 hours after the start of the release test.

Abbreviation: PTX, paclitaxel.

the $0.5 \%$ RADA 16 hydrogel, and the half-release time was $8-10$ hours. These results clearly demonstrated that a higher concentration of peptide in the hydrogel produced slower drug release rates. The initial burst effect was lower for the $1 \%$ RADA 16 hydrogel compared with the $0.5 \%$ RADA 16 hydrogel, and an increase in peptide concentration slowed the release rates of the loaded drug, resulting in a longer half-release time for the PTX. The atomic force microscopic image showed that many nanoparticles were present in the supernatant of the release medium (Figure 8A), and the width and height of the nanoparticles were $83.1 \pm 30.3 \mathrm{~nm}$ and $4.9 \pm 2.9 \mathrm{~nm}$, respectively. However, sodium dodecyl sulfate was also an amphiphilic molecule, which might form assemblies in aqueous solution. Thus, an additional atomic force microscopy test with only sodium dodecyl sulfate in the release medium was performed to verify this result. The resulting images showed that sodium dodecyl sulfate was obviously accumulated on the surface of mica, and no similar size of nanoparticles formed (data not shown). These data suggest that PTX was encapsulated in peptide nanofibers and that RADA16-PTX nanoparticles were formed in the release process. A schematic representation of a possible model for PTX release from the PTX-RADA16 hydrogel is shown in Figure 8B. Considering the data from morphology and rheology analysis, it was found that the higher concentration of peptide solution had more cross-linked nanofibers and led to the formation of a more elastic hydrogel. Because hydrogel formed from a higher concentration of peptide showed increased stability with a higher density of nanofibers and smaller sizes of pores, the probability of specific interactions

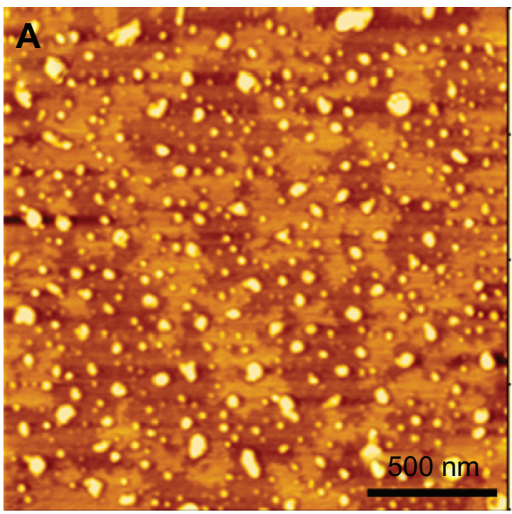

B

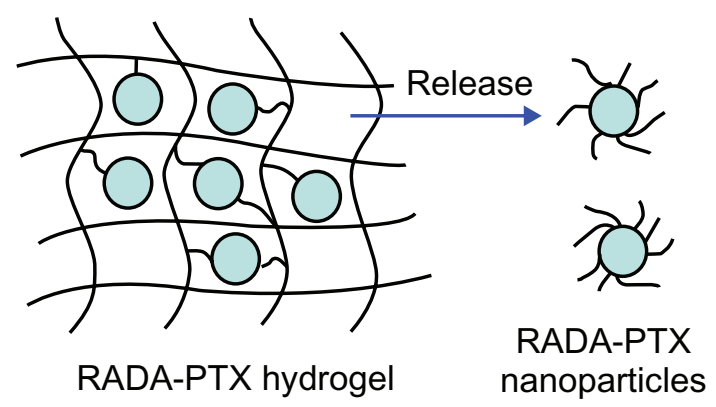

Figure 8 In vitro release of PTX from RADA I6-PTX hydrogel. (A) Atomic force microscopy image of supernatant in release medium, in which many nanoparticles could be seen. (B) schematic representation of modeling for PTX release from PTX-RADAI6 hydrogel.

Abbreviation: PTX, paclitaxel. 
between PTX and peptide nanofibers and diffusion hindrance was increased, yielding a decrease in the diffusivity of PTX and finally resulting in slower drug release rates. ${ }^{15,16}$ These results suggested that the release rates of PTX can be controlled by changing the peptide concentration, so the release time could be extended by adding a greater amount of peptide in future studies. In addition, the addition of sodium dodecyl sulfate as a surfactant can increase the release rates of PTX from the hydrogel, an effect that would be caused by the increased degradation rates of the RADA16 peptide.

\section{Inhibition of RADA I6-PTX hydrogel on the growth of tumor cells}

As an antiproliferation drug, PTX is a potent inhibitor of angiogenesis, cell migration, and collagenase production. Because it has been demonstrated that PTX has significant antitumor activity against various solid tumors, including breast cancer, the human breast cancer cell line MDAMB-435S was used to study the antitumor efficiency of the RADA16-PTX hydrogel. As in previous reports, the antiproliferative activity of the complex was dependent on the concentration of PTX. ${ }^{2}$ To simulate the in vivo situation and optimize the antitumor test, PTX10 $\mu \mathrm{g}$ was administered to each well of the 96-well plate, and the culture medium was changed every day. In our study, the data showed that single use of RADA16 produced no inhibition of tumor cell proliferation, while the RADA16-PTX hydrogel inhibited growth of tumor cells effectively. As shown in Figure 9, there was no significant difference in cell viability rates between the PTX-treated group and both RADA16-PTX-treated groups at day 1 . At day 3 , there was a significant difference between the PTX group and the 1\% RADA16-PTX group, but there was no significant difference between the $0.5 \%$ and 1\% RADA16-PTX groups. At days 5 and 7, compared with the PTX group, both RADA16-PTX groups demonstrated lower cell viability rates, and the cell viability rate in the $1 \%$ RADA16-PTX group was significantly lower than that in the $0.5 \%$ RADA16-PTX group. These data suggest that PTX and $0.5 \%$ RADA16-PTX had poor ability to inhibit cell growth after days 3 and 5, respectively, whereas 1\% RADA16-PTX hydrogel maintained relatively high inhibitory activity even at day 7 . It was concluded that the RADA16 hydrogel could control release of PTX effectively and that a higher concentration of peptide hydrogel resulted in an increased release time for PTX. This result was in accordance with those from the in vitro release test. The fluorescence images showed that the tumor cells in the RADA16 group continued to proliferate over the course of the observed days (Figure 10). By contrast, in the PTX group and both RADA16-PTX groups, only a few cells could be seen at day 3 , which indicated that cell proliferation was inhibited by PTX. However, the number of tumor cells in the PTX group was slightly higher than that in both

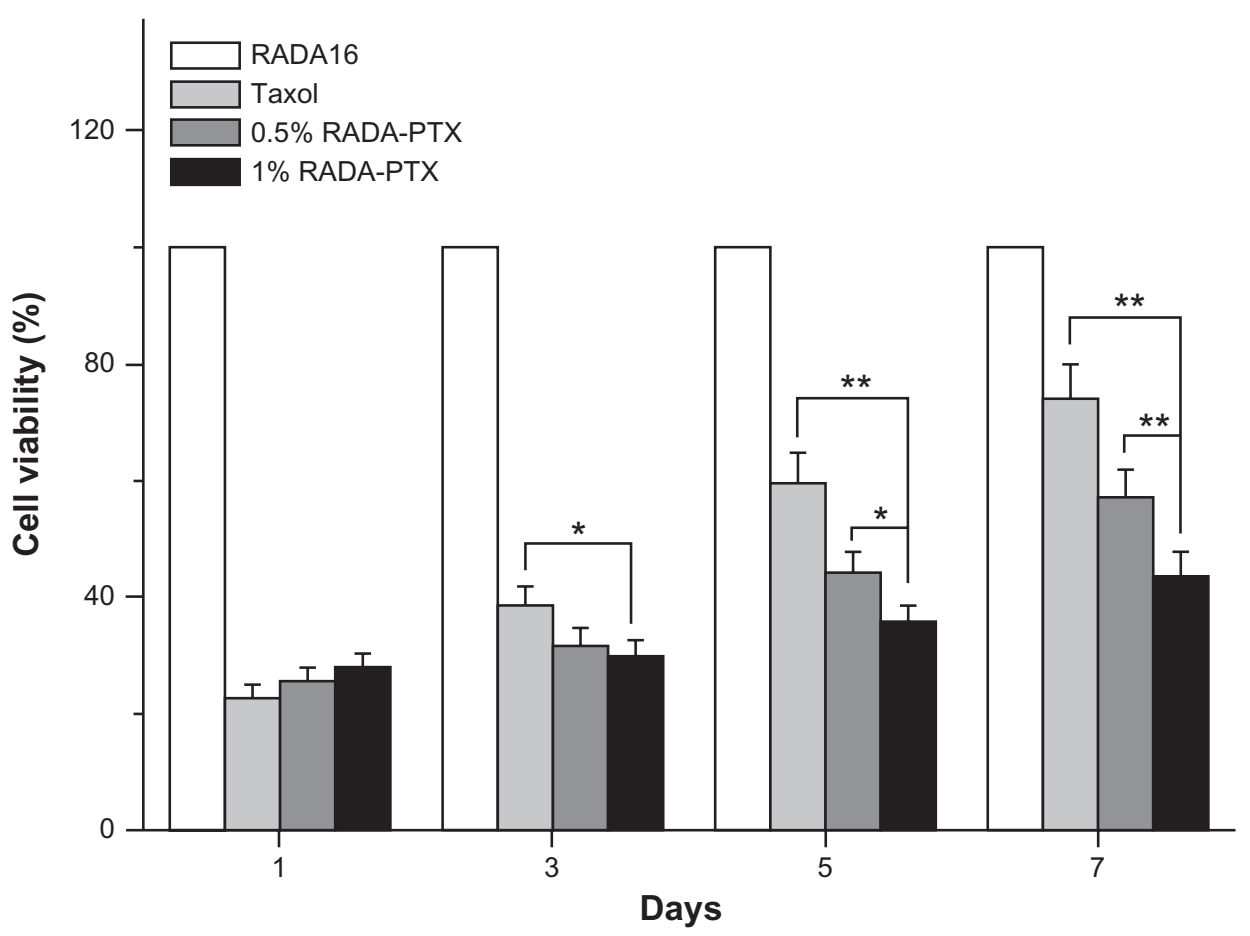

Figure 9 Inhibitory effect of RADA 16, PTX and RADA I6-PTX hydrogel with different peptide concentrations on the growth of MDA-MB-435S cells in vitro. Abbreviation: PTX, paclitaxel. 


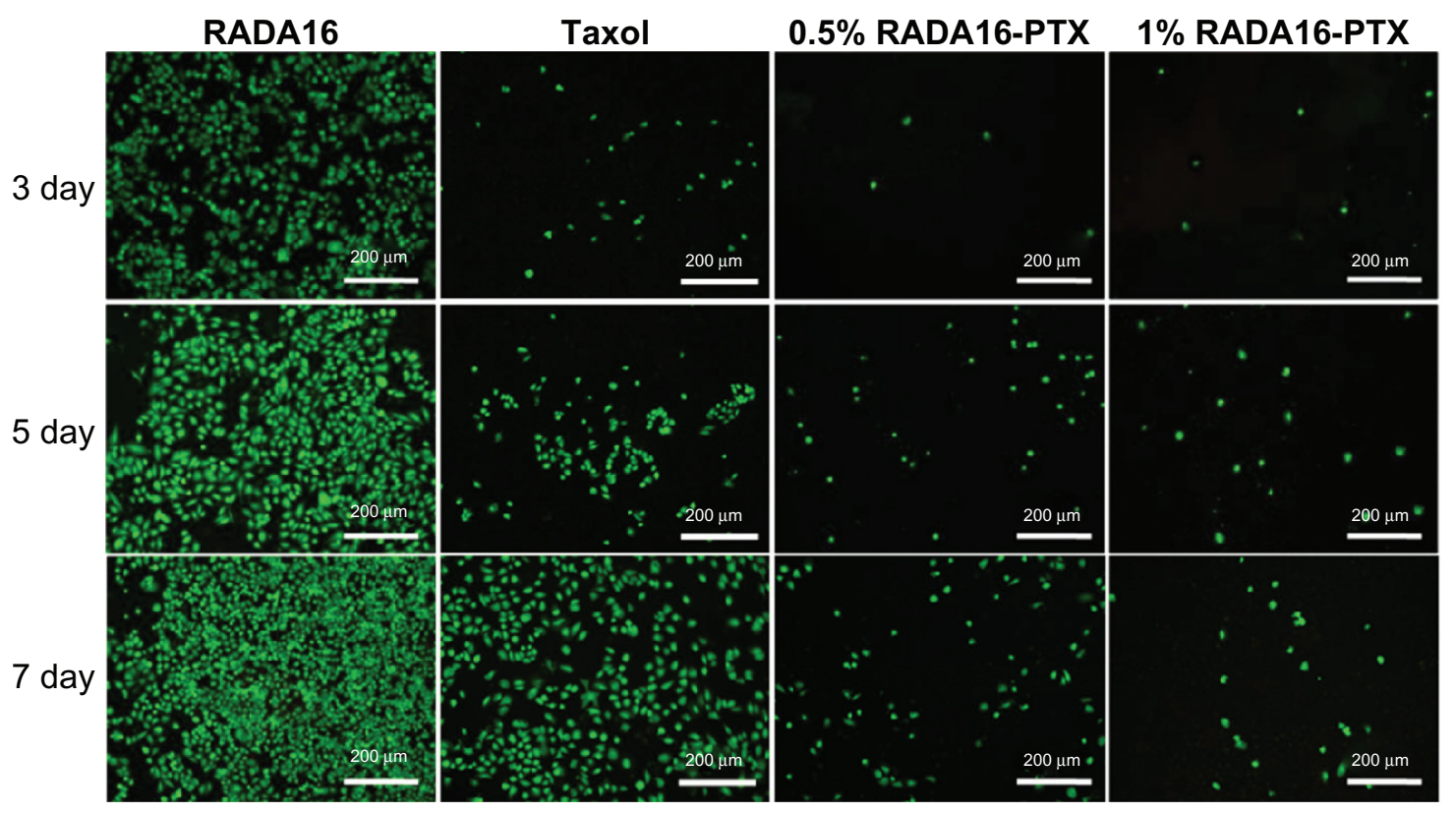

Figure 10 Cell viability assessment by the Live/Dead assay method after treatment with RADAI6, PTX, or RADAI6-PTX hydrogel with different peptide concentrations. Abbreviation: PTX, paclitaxel.

RADA16-PTX groups. At day 5 , in comparison with the $1 \%$ RADA16-PTX group, more tumor cells were observed in the PTX and 0.5\% RADA16-PTX groups. At day 7, compared with previous days, an increased number of tumor cells was observed in the PTX group and both RADA16-PTX groups, but fewer cells were seen in the 1\% RADA16-PTX group than those in the PTX group and the 0.5\% RADA16-PTX group. It was concluded that the 1\% RADA16-PTX hydrogel had a longer lasting inhibitory effect on proliferation of tumor cells than did the other tested groups.

These results indicate that the self-assembling peptide system could be used to control the release of PTX. The release time of PTX from the hydrogel showed increased correlation with the concentration of peptide, and a more elastic hydrogel led to stronger interactions between the drug and the nanofibers, which decreased the diffusion rates of PTX and resulted in longer drug release times. The spontaneously gelling ability of RADA16-PTX suspension in an ionic environment provided the controlled release of PTX, which would increase the contact time of drug at the site of action and enhance the efficiency of therapy. 5,23 Because PTX cannot differentiate between cancer and normal cells, which may result in major toxicity to normal cells, the potential application of peptide hydrogel to the localized delivery of PTX might minimize the cytotoxicity and side effects. In addition, the self-assembling peptide was a biocompatible and biodegradable nanomaterial, which previous studies have reported to produce no toxic and immune response, and this material has been widely used for cell culture and injection into animals. ${ }^{24-26}$ Therefore, it suggested that this self-assembling peptide is a favorable vehicle for local PTX delivery as an in situ-forming hydrogel system. Nevertheless, further experiments are still needed to estimate the antitumor efficiency of the peptidePTX system in vivo.

\section{Conclusion}

In conclusion, this study found that the RADA16-PTX complex could form colloidal suspensions after magnetic stirring for 48 hours and that PTX was stabilized in RADA16-containing aqueous solutions. RADA16-PTX suspensions were able to form hydrogel spontaneously in ionic solutions. The RADA16-PTX hydrogel formed was of high elasticity and demonstrated controlled drug release properties. The RADA16 hydrogel prolonged the inhibitory effect of PTX on growth of breast cancer cells in vitro. This injectable, in situ-forming hydrogel system has great potential as a delivery vehicle for various hydrophobic drugs in future studies.

\section{Acknowledgments}

The authors would like to thank Hua Li for the high-pressure liquid chromatography measurements. This work was supported by the Chinese National 985 Project of Education Ministry to Sichuan University and by the National Natural Science Foundation of china (Grant No. 31070889). 


\section{Disclosure}

The authors report no conflicts of interest in this work.

\section{References}

1. Ruel-Gariepy E, Shive M, Bichara A, et al. A thermosensitive chitosan-based hydrogel for the local delivery of paclitaxel. Eur J Pharm Biopharm. 2004;57:53-63.

2. Obara K, Ishihara M, Ozeki Y, et al. Controlled release of paclitaxel from photocrosslinked chitosan hydrogels and its subsequent effect on subcutaneous tumor growth in mice. J Control Release. 2005;110: 79-89.

3. Dhanikula AB, Panchagnula R. Localized paclitaxel delivery. Int $J$ Pharm. 1999;183:85-100.

4. Dordunoo SK, Oktaba AMC, Hunter W, et al. Release of Taxol from poly(epsilon-caprolactone) pastes: Effect of water-soluble additives. J Control Release. 1997;44:87-94.

5. Ta HT, Dass CR, Dunstan DE. Injectable chitosan hydrogels for localised cancer therapy. J Control Release. 2008;126:205-216.

6. Hoare TR, Kohane DS. Hydrogels in drug delivery: Progress and challenges. Polymer. 2008;49:1993-2007.

7. He C, Kim SW, Lee DS. In situ gelling stimuli-sensitive block copolymer hydrogels for drug delivery. J Control Release. 2008;127:189-207.

8. Hiemstra C, Zhong Z, Van Tomme SR, et al. In vitro and in vivo protein delivery from in situ forming poly(ethylene glycol)-poly(lactide) hydrogels. J Control Release. 2007;119:320-327.

9. Ruel-Gariepy E, Leclair G, Hildgen P, Gupta A, Leroux JC. Thermosensitive chitosan-based hydrogel containing liposomes for the delivery of hydrophilic molecules. J Control Release. 2002;82:373-383.

10. Liu J, Song H, Zhang L, Xu H, Zhao X. Self-assembly-peptide hydrogels as tissue-engineering scaffolds for three-dimensional culture of chondrocytes in vitro. Macromol Biosci. 2011;10:1164-1170.

11. Zhao X, Zhang S. Molecular designer self-assembling peptides. Chem Soc Rev. 2006;35:1105-1110.

12. Zhao X, Zhang S. Designer self-assembling peptide materials. Macromol Biosci. 2007;7:13-22.

13. Keyes-Baig C, Duhamel J, Fung SY, Bezaire J, Chen P. Self-assembling peptide as a potential carrier of hydrophobic compounds. J Am Chem Soc. 2004;126:7522-7532.
14. Zhao X, Zhang S. Fabrication of molecular materials using peptide construction motifs. Trends Biotechnol. 2004;22:470-476.

15. Nagai Y, Unsworth LD, Koutsopoulos S, Zhang S. Slow release of molecules in self-assembling peptide nanofiber scaffold. J Control Release. 2006;115:18-25.

16. Koutsopoulos S, Unsworth LD, Nagai Y, Zhang S. Controlled release of functional proteins through designer self-assembling peptide nanofiber hydrogel scaffold. Proc Natl Acad Sci U S A. 2009;106:4623-4628.

17. Davis ME, Motion JP, Narmoneva DA, et al. Injectable self-assembling peptide nanofibers create intramyocardial microenvironments for endothelial cells. Circulation. 2005;111:442-450.

18. Davis ME, Hsieh PC, Takahashi T, et al. Local myocardial insulin-like growth factor 1 (IGF-1) delivery with biotinylated peptide nanofibers improves cell therapy for myocardial infarction. Proc Natl Acad Sci US A. 2006;103:8155-8160.

19. Ye Z, Zhang H, Luo H, et al. Temperature and $\mathrm{pH}$ effects on biophysical and morphological properties of self-assembling peptide RADA16-I. J Pept Sci. 2008;14:152-162.

20. Fung SY, Yang H, Chen P. Formation of colloidal suspension of hydrophobic compounds with an amphiphilic self-assembling peptide. Colloids Surf B Biointerfaces. 2007;55:200-211.

21. Wang J, Tang FS, Li F, et al. The amphiphilic self-assembling peptide EAK16-I as a potential hydrophobic drug carrier. J Nanomater. 2008;Article ID 516286.

22. Li F, Wang J, Tang F, et al. Fluorescence studies on a designed selfassembling peptide of RAD16-II as a potential carrier for hydrophobic drug. J Nanosci Nanotechnol. 2009;9:1611-1614.

23. Kakinoki S, Taguchi T, Saito H, Tanaka J, Tateishi T. Injectable in situ forming drug delivery system for cancer chemotherapy using a novel tissue adhesive: characterization and in vitro evaluation. Eur J Pharm Biopharm. 2007;66:383-390.

24. Zhang S. Designer self-assembling peptide nanofiber scaffolds for study of 3-D cell biology and beyond. Adv Cancer Res. 2008;99: 335-362.

25. Zhang S, Gelain F, Zhao X. Designer self-assembling peptide nanofiber scaffolds for 3D tissue cell cultures. Semin Cancer Biol. 2005;15: 413-420.

26. Ellis-Behnke RG, Liang YX, You SW, et al. Nano neuro knitting: peptide nanofiber scaffold for brain repair and axon regeneration with functional return of vision. Proc Natl Acad Sci U S A. 2006;103:5054-5059.
International Journal of Nanomedicine

\section{Publish your work in this journal}

The International Journal of Nanomedicine is an international, peerreviewed journal focusing on the application of nanotechnology in diagnostics, therapeutics, and drug delivery systems throughout the biomedical field. This journal is indexed on PubMed Central, MedLine, CAS, SciSearch $®$, Current Contents ${ } /$ Clinical Medicine,

\section{Dovepress}

Journal Citation Reports/Science Edition, EMBase, Scopus and the Elsevier Bibliographic databases. The manuscript management system is completely online and includes a very quick and fair peer-review system, which is all easy to use. Visit http://www.dovepress.com/ testimonials.php to read real quotes from published authors. 